\title{
Why we need more septal myectomy surgeons: An emerging recognition
}

\author{
Barry J. Maron, MD, ${ }^{\mathrm{a}}$ Joseph A. Dearani, MD, ${ }^{\mathrm{b}}$ Martin S. Maron, MD, ${ }^{\mathrm{a}}$ Steve R. Ommen, MD, ${ }^{\mathrm{b}}$ \\ Hassan Rastegar, MD, ${ }^{\mathrm{a}}$ Rick A. Nishimura, MD, ${ }^{\mathrm{b}}$ Daniel G. Swistel, MD, ${ }^{\mathrm{c}}$ Mark V. Sherrid, MD, \\ Anthony Ralph-Edwards, MD, ${ }^{\mathrm{d}}$ Harry Rakowski, MD, ${ }^{\mathrm{d}}$ Nicholas G. Smedira, MD, ${ }^{\mathrm{e}}$ Ethan J. Rowin, MD, ${ }^{\mathrm{a}}$ \\ Milind Y. Desai, MD, ${ }^{\mathrm{e}}$ Harry M. Lever, MD, ${ }^{\mathrm{e}}$ Paolo Spirito, MD, ${ }_{\mathrm{f}}^{\mathrm{P}}$ Paolo Ferrazzi, $\mathrm{MD},{ }^{\mathrm{f}}$ and \\ Hartzell V. Schaff, MD $^{\mathrm{b}}$
}

\footnotetext{
$\overline{\text { From the }{ }^{\mathrm{a}} \mathrm{HCM}}$ Institute, Division of Cardiology, Tufts Medical Center, Boston, Mass; ${ }^{\mathrm{b}}$ Mayo Clinic, Rochester, Minn; ${ }^{\mathrm{c}}$ New York University Langone Medical Center, New York, NY; ${ }^{\mathrm{d}}$ Toronto General Hospital, University Health Network, Toronto, Ontario, Canada; ${ }^{\mathrm{e}}$ Cleveland Clinic Foundation, Cleveland, Ohio; and ${ }^{\mathrm{f}}$ Policlinico di Monza, Monza, Italy.

Received for publication Oct 15, 2016; revisions received Nov 21, 2016; accepted for publication Dec 15, 2016; available ahead of print March 6, 2017

Address for reprints: Barry J. Maron, MD, HCM Institute, Division of Cardiology, Tufts Medical Center, 800 Washington St, \#70, Boston, MA 02111 (E-mail: barrymaron1@gmail.com).

J Thorac Cardiovasc Surg 2017; 154:1681-5

$0022-5223 / \$ 36.00$

Copyright (C) 2017 by The American Association for Thoracic Surgery

http://dx.doi.org/10.1016/j.jtcvs.2016.12.038
}

Hypertrophic cardiomyopathy (HCM) is a diverse genetic heart disease, which while compatible with normal life expectancy, also may be associated with disabling symptoms or adverse events. ${ }^{2,3}$ With the decrease in highly visible HCM-related sudden deaths due to the penetration of implantable cardioverter-defibrillators into this population, it is perhaps under-appreciated that currently the most common element of the overall HCMdisease burden is progressive heart failure refractory to maximal medical management (usually judged as New York Heart Association [NYHA] functional classes III/ IV). ${ }^{2,3}$ This subgroup includes some patients with nonobstructive disease who may become candidates for heart transplantation, ${ }^{3}$ but also a larger proportion with drug refractory heart failure due to dynamic left ventricular (LV) outflow tract obstruction. ${ }^{1-7}$ These latter patients are candidates for the ventricular septal myectomy operation, ${ }^{1,4-13}$ or in selected cases percutaneous alcohol septal ablation. ${ }^{3,5,6}$

\section{THE MYECTOMY EXPERIENCE}

An extensive experience over more than 50 years has conclusively shown myectomy to reliably relieve LV outflow gradient and normalize LV pressures, thereby improving NYHA class and quality of life in almost $90 \%$ of patients. $1,3,4,10,11$ Furthermore, patients who undergo septal myectomy experience enhanced survival similar to that of an age- and sex-matched general population, and also a possible reduction in sudden death risk (Figure 1). ${ }^{1,4}$

Myectomy continues to be the primary and preferred treatment option for severely symptomatic patients with LV outflow obstruction (Figures 1 and 2), ${ }^{1-6,10,11,13}$ as evident by expert consensus recommendations such as the 25 years.

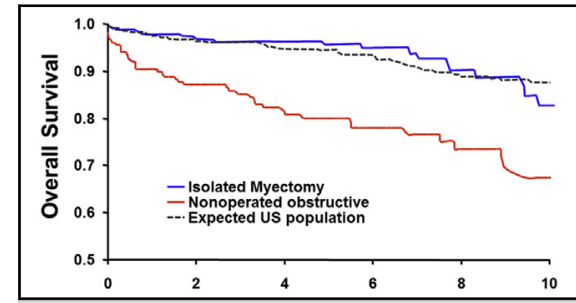

Mortality after myectomy is no different from expected in the US population. From Ommen et al.

\section{Central Message}

There are currently an inadequate number of expert cardiac surgeons performing the septal myectomy operation. Therefore, it is important to promote this procedure and bring cardiac surgery to more patients with severely symptomatic obstructive hypertrophic cardiomyopathy.

See Editorial Commentary page 1686.

2011 U.S./Canada guidelines (American College of Cardiology/American Heart Association [ACC/AHA]), and also based on substantial clinical experience. ${ }^{1-6,10-13}$ Indeed, myectomy has survived more than 50 years as the standard despite the challenges from dual-chamber pacing and percutaneous alcohol ablation over the past

The septal myectomy operation involves resection of muscle from the anterior portion of ventricular septum, beginning at the base just below the aortic valve, and extending beyond the point of outflow obstruction (ie, mitral valve-septal contact). Originally designed and promoted by Dr Andrew G. Morrow at the National Institutes of Health (Bethesda, Md) in the early 1960s, the Morrow procedure was quickly adopted by cardiac surgeons at other US and international institutions. With continued experience, however, it became clear that the original Morrow myectomy was limited in width and length, associated with incomplete LV outflow gradient relief in a minority of patients. $8,9,12,13$ A more "extended" myectomy was first described by Messmer, ${ }^{8}$ and other surgeons who made minor modifications to the procedure, ${ }^{9,12}$ with the important principle of creating a 


\section{Abbreviations and Acronyms \\ ACC/AHA $=$ American College of Cardiology/ American Heart Association \\ HCM = hypertrophic cardiomyopathy \\ $\mathrm{LV} \quad=$ left ventricular \\ NIS $\quad=$ Nationwide Inpatient Sample \\ NYHA $=$ New York Heart Association}

sufficiently wide and long muscular resection extending beyond the endocardial [contact] lesion and the mitral valve coaptation plane, to permit identification of structures relevant to surgical relief of outflow obstruction (eg, mitral valve elongation, anomalous papillary muscle direct insertion into mitral valve, or other anomalous muscle bundles or chordae). ${ }^{13-16}$

The initial euphoria for alcohol ablation, as a percutaneous nonsurgical approach beginning in the late $1990 \mathrm{~s}$, refocused attention on outflow obstruction, paradoxically resulting in increased numbers of myectomy referrals. This increase in myectomy volume could also be due to recognition that in a substantial proportion of patients alcohol septal ablation can not be performed successfully given several anatomic issues: Suboptimal septal perforation, massive LV hypertrophy, concomitant coronary artery disease, or mitral valve/papillary muscle abnormalities.

Increase in myectomy surgery has been associated with the growth of dedicated HCM Centers of Excellence ${ }^{17}$ in which a dramatic decrease in operative mortality for surgical myectomy has been witnessed. ${ }^{18}$ Indeed, current operative mortality in almost 3700 isolated myectomies performed over the most recent 15 years by surgeons experienced with this procedure at 5 major high-volume dedicated North American HCM centers is low, 0.4\%, now making it the safest open-heart procedure. ${ }^{18}$

\section{COMMUNITY HOSPITAL MYECTOMIES}

Data from the US Nationwide Inpatient Sample (NIS) Database 1998-2011, in $2014^{19}$ and again in 2016, ${ }^{20}$ reported a much higher operative mortality for myectomy of up to $6 \%$, when performed in community hospital settings (eg, nonfederal, short-term, general, and specialty hospitals). Although this survey is characterized as representative of US hospitals, it includes only $20 \%$ of such institutions. Nevertheless, these NIS data underscore the important surgical principle that higher operative mortality (and comorbidity burden) are associated with lower patient volume, also applicable to other operations that require a high level of specialization and experience like myectomy. ${ }^{20,21}$

We are concerned that these data from NIS significantly overestimate the risk attached to the classic myectomy

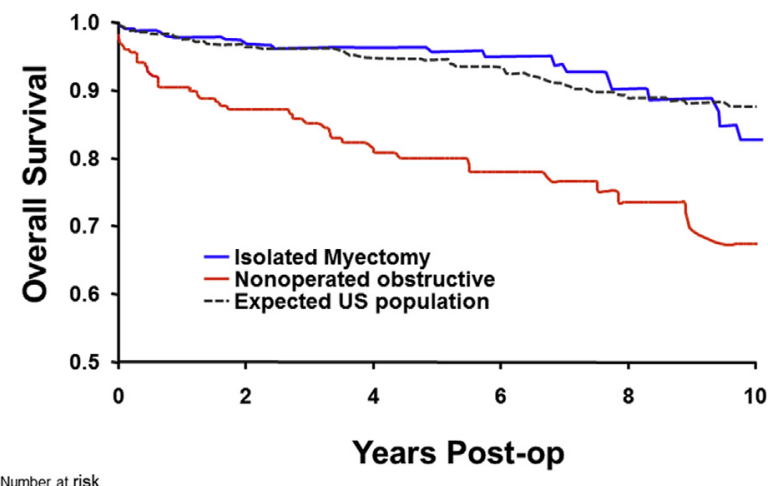

Number at risk

\begin{tabular}{|c|c|c|c|c|c|c|}
\hline Myectomy & 289 & 249 & 179 & 108 & 66 & 39 \\
\hline $\begin{array}{l}\text { Nonoperated } \\
\text { obstructive }\end{array}$ & 228 & 146 & 106 & 69 & 42 & 28 \\
\hline
\end{tabular}

FIGURE 1. Mortality after myectomy is no different from expected in the US population. From Ommen and colleages. ${ }^{1}$

operation, when performed by surgeons with sufficient procedural experience. Reporting such a potentially exaggerated operative risk from NIS can only confuse patients with obstructive HCM and the practicing community, thereby distorting proper management of this disease. Notably, the substantial proportion of patients in the NIS survey having concomitant mitral or aortic valve replacement, coronary artery bypass surgery, and iatrogenic ventricular septal defect raises the legitimate concern that many of these patients either may not have had true HCM and/or the myectomy operation may have been performed by surgeons at centers without

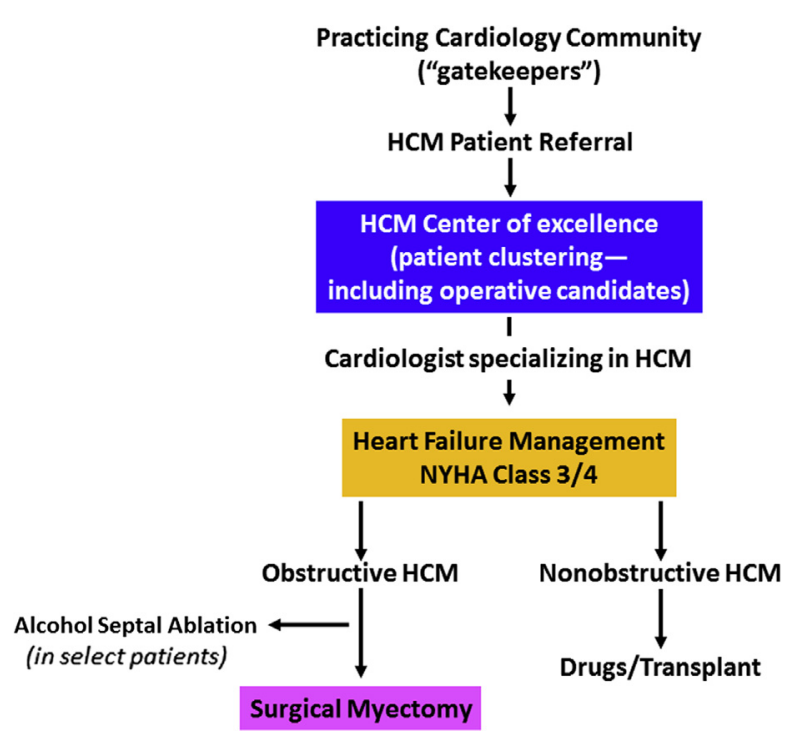

FIGURE 2. Flow diagram of patient referral structure leading to surgical myectomy. HCM, Hypertrophic cardiomyopathy; NYHA, New York Heart Association. 
clinical experience with HCM. $^{19-21}$ Mitral valve replacement in young patients with HCM is a particular concern for management, given that the abolition of outflow tract obstruction achieved is only then replaced with the risk for complications associated with prosthetic valves. ${ }^{22}$ In addition, the high incidence of permanent complete heart block reported in the NIS operative survey, but rare with expert myectomy surgeons, ${ }^{5,6,9-14}$ is a concern because it leads to pacemaker dependency. The possibility of requiring permanent pacemakers after alcohol ablation is often a pivotal decision point for those who elect myectomy. ${ }^{5}$

\section{THE CLINICAL DILEMMA}

This debate concerning operative risk in obstructive $\mathrm{HCM}$ underscores a clinical dilemma at this crossroads in the contemporary management of this complex disease. On one hand, we and other experts accept that septal myectomy is an unusual operation, and for the likelihood of success it should be performed by surgeons with myectomy experience working in a cardiology environment familiar with HCM. ${ }^{1,4-6,9-13,17}$ Indeed, there is an acknowledged direct correlation between procedural volume (and myectomy experience) and preferred surgical outcome. Achieving optimal operative results cannot be expected with a low-volume exposure to HCM. ${ }^{18-20}$ This assertion comes largely from certain unique anatomic features of the LV outflow tract and the operation; that is, performed through an aortotomy with limited visual exposure of the field of interest, as well as the heterogeneous and variable morphology of ventricular septum, LV outflow tract, and mitral valve $\mathrm{e}^{4-6,10-14,16,22}$ requiring pre- and postoperative echocardiographic imaging and hemodynamic monitoring in the operating room. ${ }^{23}$

On the other hand, we cannot afford to limit myectomy to only a very few surgeons in the world. Indeed, although it is critical for the myectomy surgeon to be exposed to an adequate volume of deserving operative candidates, some demystification of the operation is necessary to allow greater penetration into the HCM patient population. In retrospect, in the early period of 1960 to 1990, many HCM investigators and surgeons may have held too stringently to the mantra that the myectomy operation must be strictly limited to a highly select small group of programs, and in the process unintentionally suppressing dissemination of the operation to deserving patients.

\section{THE UNIQUE ASPECTS OF MYECTOMY}

Nevertheless, it is important for surgeons new to myectomy to acquire an understanding of the diverse and complex anatomy and pathophysiology of the LV outflow tract and obstruction that often must be tailored to individual patients with HCM..$^{9-17}$ Previous surgical experience and familiarity with congenital heart diseases associated with LV outflow tract obstruction, such as discrete subaortic membrane or fibromuscular tunnel or other complex cardiac anomalies, as well as mitral valve repair, are exceedingly valuable and contribute to reducing mortality and complications with septal myectomy.

Although there are no data defining an operator "learning curve" for myectomy, ${ }^{5}$ the US/Canada (ACC/AHA) HCM consensus guidelines stipulate a minimum standard of 20 myectomy operations per year for a surgical team to accrue and maintain sufficient expertise. ${ }^{5}$ Clearly, myectomy should be discouraged in small community hospital settings and dedicated private practices (without the features of HCM Centers of Excellence) in which operative results are not reported in a systematic and peer-reviewed fashion. ${ }^{19-21}$ This impetus to refer symptomatic obstructive patients for septal myectomy to specialized centers with focused cardiologic, surgical, and anesthesia expertise in HCM is reminiscent of initiatives for mitral valve repair, ${ }^{24}$ valve sparing repair of aortic aneurysms in Marfan syndrome, ${ }^{25}$ and transcatheter aortic valve replacement. ${ }^{26}$

\section{MENTORSHIP}

The 7 myectomy surgeons who have authored this commentary stand willing to directly instruct others who wish to take advantage of mentorship. ${ }^{17,27}$ This issue of mentorship for surgeons new to myectomy, for the purpose of gaining needed experience with the operation, could potentially represent a practical impediment to increasing the number of surgeons for the HCM patient population. Although there may not be a universally workable solution to this unique circumstance, it remains important to continue the commitment to regional multidisciplinary centers as models of excellence. In turn, these centers create an independent infrastructure providing sufficient surgical volume to achieve superior myectomy results. It is our expectation that within HCM centers the surgical expertise would be passed down and perpetuate over time by mentorship within these institutions. Other initiatives to consider would be establishing formal fellowships in myectomy by surgical societies or major programs, such as proposed for ventricular assist devices or heart transplantation, or possibly the development of surgical simulators specific for myectomy. ${ }^{28}$

Presently, in the United States and Canada, there are only a few established myectomy centers, including the Mayo Clinic and Cleveland Clinic as the largest, but also Toronto General, New York University, and Tufts Medical Center. Internationally, there are strong myectomy programs in Italy, Israel, Belgium, The Netherlands, and China ${ }^{13,29-31}$ 
TABLE 1. Major active myectomy surgeons*

\begin{tabular}{|c|c|c|}
\hline Name & Institution & Country \\
\hline Joseph Dearani & Mayo Clinic & USA (Rochester, Minn) \\
\hline Hartzell Schaff & Mayo Clinic & USA (Rochester, Minn) \\
\hline Nicholas Smedira & Cleveland Clinic & USA (Cleveland, Ohio) \\
\hline Hassan Rastegar & Tufts Medical Center & USA (Boston, Mass) \\
\hline Paolo Ferrazzi & Policlinico di Monza & Italy (Monza) \\
\hline Jan Nijs & UZ Brussels & Belgium (Brussels) \\
\hline Ehud Raanani & Sheba Medical Center & Israel (Tel Aviv) \\
\hline Daniel Swistel & New York University & USA (New York, NY) \\
\hline $\begin{array}{l}\text { Anthony } \\
\text { Ralph-Edwards }\end{array}$ & $\begin{array}{l}\text { Toronto General } \\
\text { Hospital }\end{array}$ & Canada (Toronto, Ontario) \\
\hline Peter L. de Jong & $\begin{array}{l}\text { Erasmus Medical } \\
\text { Center }\end{array}$ & $\begin{array}{l}\text { The Netherlands } \\
\text { (Rotterdam) }\end{array}$ \\
\hline Shuiyun Wang & Fuwai Hospital & China (Beijing) \\
\hline
\end{tabular}

*>100 myectomies performed.

(Table 1), but the survival of myectomy and its expansion in Europe has been slow. ${ }^{32}$ With greater visibility and attention directed toward outflow obstruction in HCM we have witnessed increasing numbers of obstructive (and nonobstructive) patients referred to dedicated HCM Centers of Excellence ${ }^{17,33}$ offering a full range of management options, of which a successful myectomy program is a key element.

\section{THE TEAM APPROACH AND HCM CENTERS}

Notably, a myectomy program starts with surgeons experienced with HCM and the myectomy operation. However, deserving emphasis is the important role of multidisciplinary HCM centers of excellence in providing a milieu in which cardiologists familiar with HCM interact with surgeons and patients to create a safe and effective treatment environment for this disease. ${ }^{17,33}$ Clustering patients in dedicated HCM centers with a team approach, including expertise in relevant specialties, such as imaging and anesthesia, is critical to creating an adequate myectomy case volume and operative experience, thereby ensuring the most favorable procedural outcomes.

We believe fully informed severely symptomatic patients with obstructive HCM should have, in the context of full disclosure and shared decision-making, access and the opportunity to choose the septal reduction treatment option they prefer (Figure 2). Transparency is necessary in the shared decision-making process in which the patient understands the risks and benefits and likely outcomes of both surgery and ablation at the particular institution. Also relevant is the fact that referral patterns for myectomy are highly dependent on the willingness of "gatekeeper" cardiologists to consider surgery over alcohol ablation as the first option for relieving outflow obstruction in their severely symptomatic patients. Inadequate availability of expert myectomy creates a vacuum, ultimately filled by greater numbers of patients undergoing the often less-desirable percutaneous alcohol ablation, a surgical alternative intended only for selected patients who may not be optimal candidates for surgery based on the guidelines. ${ }^{5,6}$ Increasing patient referrals to institutions with HCM specialization will create the opportunity for more expert surgeons (and HCM surgical centers) to provide the preferred treatment intervention to a greater number of patients with HCM, with the likelihood of reversing profound heart failure.

\section{CONCLUSIONS}

The current inadequate number of expert myectomy surgeons represents a significant clinical issue for patients with HCM and a major impediment to optimal management of the disease. Therefore, the message of this consensus commentary, supported and coauthored by 7 surgeons with extensive septal myectomy experience, is the importance of promoting this operation and in the process bringing other expert cardiac surgeons to the patients with severely symptomatic obstructive HCM. This initiative seems imperative, given the many thousands of such patients now identified in increasing numbers who would benefit from surgical myectomy, both in terms of quality of life and duration.

\section{Conflict of Interest Statement}

Authors have nothing to disclose with regard to commercial support.

\section{References}

1. Ommen SR, Maron BJ, Olivotto I, Maron MS, Cecchi F, Betocchi S, et al. Long-term effects of surgical septal myectomy on survival in patients with obstructive hypertrophic cardiomyopathy. J Am Coll Cardiol. 2005;46: 470-6.

2. Maron BJ, Rowin EJ, Casey SA, Maron MS. How hypertrophic cardiomyopathy became a contemporary treatable genetic disease with low mortality: shaped by 50 years of clinical research and practice. JAMA Cardiol. 2016;1:98-105.

3. Maron BJ, Ommen SR, Semsarian C, Spirito P, Olivotto I, Maron MS. State-ofthe-art review. Hypertrophic cardiomyopathy: present and future, with translation into contemporary cardiovascular medicine. J Am Coll Cardiol. 2014;64:83-99.

4. Woo A, Williams WG, Choi R, Wigle ED, Rozenblyum E, Fedwick K, et al. Clinical and echocardiographic determinants of long-term survival after surgical myectomy in obstructive hypertrophic cardiomyopathy. Circulation. 2005;111: 2033-41.

5. Gersh BJ, Maron BJ, Bonow RO, Dearani JA, Fifer MA, Link MS, et al. 2011 ACCF/AHA guidelines for the diagnosis and treatment of hypertrophic cardiomyopathy. Circulation. 2011;124:2761-96.

6. Maron BJ, McKenna WJ, Danielson GK, Kappenberger LJ, Kuhn HJ, Seidman CE, et al. American College of Cardiology/European Society of Cardiology Clinical Expert Consensus Document on Hypertrophic Cardiomyopathy. J Am Coll Cardiol. 2003;42:1687-713.

7. Morrow AG, Lambrew CT, Braunwald E. Idiopathic hypertrophic subaortic stenosis. II. Operative treatment and the results of pre- and postoperative hemodynamic evaluations. Circulation. 1964;30:120-51.

8. Messmer BJ. Extended myectomy for hypertrophic obstructive cardiomyopathy. Ann Thorac Surg. 1994;58:575-7. 
9. Schaff HV, Said S. Transaortic extended septal myectomy for hypertrophic cardiomyopathy. Oper Techn Thorac Cardiovasc Surg. 2012;4:238-50.

10. Smedira NG, Lytle BW, Lever HM, Rajeswaran J, Krishnaswamy G, Kaple RK, et al. Current effectiveness and risks of isolated septal myectomy for hypertrophic obstructive cardiomyopathy. Ann Thorac Surg. 2008;85:127-33.

11. Desai MY, Smedira NG, Bhonsale A, Thamilarasa M, Lytle BW, Lever HM. Symptom assessment and exercise impairment in surgical decision making in hypertrophic obstructive cardiomyopathy: relationship to outcomes. J Thorac Cardiovasc Surg. 2015;150:928-35.

12. Minakata K, Dearani JA, Nishimura RA, Maron BJ, Danielson GK. Extended septal myectomy for hypertrophic obstructive cardiomyopathy with anomalous mitral papillary muscles or chordae. J Thorac Cardiovasc Surg. 2004; 127:481-9.

13. Ferrazzi P, Spirito P, Iacovoni A, Calabrese A, Migliorati K, Simon C, et al. Transaortic chordal cutting: mitral valve repair for obstructive hypertrophic cardiomyopathy with mild septal hypertrophy. JAm Coll Cardiol. 2015;66:1687-96.

14. Sherrid MV, Balaram S, Kim B, Axel L, Swistel DG. The mitral valve in obstructive hypertrophic cardiomyopathy: a test in context. J Am Coll Cardiol. 2016;67:1846-58.

15. Kwon DH, Smedira NG, Thamilarasan M, Lytle BW, Lever H, Desai MY. Characteristics and surgical outcomes of symptomatic patients with hypertrophic cardiomyopathy with abnormal papillary muscle morphology undergoing papillary muscle reorientation. J Thorac Cardiovasc Surg. 2010;140:317-24.

16. Klues HG, Roberts WC, Maron BJ. Anomalous insertion of papillary muscle directly into anterior mitral leaflet in hypertrophic cardiomyopathy. Significance in producing left ventricular outflow obstruction. Circulation. 1991;84:1188-97.

17. Maron BJ, Rastegar H, Udelson JE, Dearani JA, Maron MS. Contemporary surgical management of hypertrophic cardiomyopathy, the need for more myectomy surgeons and disease-specific centers, and the Tufts initiative. Am J Cardiol. 2013;112:1512-5.

18. Maron BJ, Dearani JA, Ommen SR, Maron MS, Schaff HV, Nishimura RA, et al. Low operative mortality achieved with surgical septal myectomy: role of dedicated hypertrophic cardiomyopathy centers in the management of dynamic subaortic obstruction. J Am Coll Cardiol. 2015;66:1307-8.

19. Panaich SS, Badheka AO, Chothani A, Mehta K, Patel NJ, Deshmukh A, et al. Results of ventricular septal myectomy and hypertrophic cardiomyopathy (from Nationwide Inpatient Sample [1998-2010]). Am J Cardiol. 2014;114:1390-5.

20. Kim LK, Swaminathan RV, Looser P, Minutello RM, Wong SC, Bergman G, et al. Impact of hospital volume on outcomes after septal myectomy and alcohol septal ablation for treatment of obstructive hypertrophic cardiomyopathy, U.S. Nationwide Inpatient Database 2003-2011. JAMA Cardiol. 2016;1:324-32.
21. Ommen SR, Nishimura RA. Hypertrophic cardiomyopathy-one case per year? A clarion call to do what is right. JAMA Cardiol. 2016;1:333-4.

22. Hong JH, Schaff HV, Nishimura RA, Abel MD, Dearani JA, Li Z, et al. Mitral regurgitation in patients with hypertrophic obstructive cardiomyopathy Implications for concomitant valve procedures. J Am Coll Cardiol. 2016;68: 1497-504.

23. Ashikhmina EA, Schaff HV, Ommen SR, Dearani JA, Nishimura RA, Abel MD Intraoperative direct measurement of left ventricular outflow tract gradients to guide surgical myectomy for hypertrophic cardiomyopathy. J Thorac Cardiovasc Surg. 2011;142:53-9.

24. Bonow RO, Adams DH. The time has come to define centers of excellence in mitral valve repair. J Am Coll Cardiol. 2016;67:499-501.

25. Coselli JS, Volguina IV, LeMaire SA, Sundt TM, Connolly HM, Stephens EH, et al. Aortic valve operative outcomes in Marfan patients study group. Early and 1-year outcomes of aortic root surgery in patients with Marfan syndrome: a prospective, multicenter, comparative study. J Thorac Cardiovasc Surg. 2014;147:1758-66.

26. Bakaeen FG, Kar B, Chu D, Cornwell LD, Blaustein A, Levine GN, et al. Establishment of a transcatheter aortic valve program and heart valve team at a Veterans Affairs facility. Am J Surg. 2012;204:643-8.

27. Maron BJ, Spirito P. Surgical ventricular septal myectomy in the developing world. Am J Cardiol. 2016;117:874-7.

28. Sutherland LM, Middleton PF, Anthony A, Hamdorf J, Cregan P, Scott D Maddern GJ. Surgical simulation: a systematic review. Ann Surg. 2006;243: 291-300.

29. Vriesendorp PA, Schinkel AF, Soliman OI, Kofflard MJ, de Jong PL, van Herwerden LA, et al. Long-term benefit of myectomy and anterior mitral leaflet extension in obstructive hypertrophic cardiomyopathy. Am J Cardiol. 2015;115: $670-5$.

30. Iacovoni A, Spirito P, Simon C, Iascone M, Di Dedda G, De Filippo P, et al A contemporary European experience with surgical septal myectomy in hypertrophic cardiomyopathy. Eur Heart J. 2012;33:2080-7.

31. ten Cate FJ, Soliman OI, Michels M, Theuns DA, de Jong PL, Geleijnse ML, et al. Long-term outcome of alcohol septal ablation in patients with obstructive hypertrophic cardiomyopathy: a word of caution. Circ Heart Fail. 2010;3:362-9.

32. Maron BJ, Yacoub M, Dearani JA. Benefits of surgery for obstructive hypertrophic cardiomyopathy: bring septal myectomy back for European patients. Eur Heart J. 2011;32:1055-8.

33. Maron BJ. Hypertrophic cardiomyopathy centers. Am J Cardiol. 2009;104: 1158-9. 